\title{
SIWO MEGOU: KOREOGRAFI SIGER PEPADUN LAMPUNG
}

\author{
Luthfi Guntur Eka Putra \\ Program Pascasarjana, Institut Seni Indonesia Yogyakarta \\ Email: luthfigeputra@gmail.com
}

\section{RINGKASAN}

Siwo Megou merupakan karya tari yang berpijak pada gerak dasar tari Cangget Lampung. Karya ini terinspirasi dari kehidupan masyarakat Lampung. Siwo Megou diambil dari bahasa Lampung yang artinya Sembilan Marga. Kesembilan marga tersebut diikat oleh aliran sungai yang mengikat daerah tersebut. Kesembilan marga disatukan oleh 'alat' pemersatu yaitu siger pepadun. Kesembilan marga direpresentasikan ke dalam bentuk sebuah siger pepadun sebagai simbol persatuan. Musik yang digunakan berangkat dari tabuhan tradisi Lampung yang dikomposisi sesuai kebutuhan dan interpretasi penata. Karya ini ditarikan oleh sepuluh penari, sembilan lakilaki dan satu perempuan. Menggunakan rangsang kinestetik dan rangsang ideasional. Desain dramatik dibagi menjadi tiga segmen.

Kata kunci: siwo megou, siger, cangget.

\section{ABSTRACT}

Siwo Megou is a dance work based on the basic movements of Cangget Lampung dance. This work is inspired by the life of the people of Lampung. Siwo Megou is taken from the Lampung language, which means the Nine Clans. The nine clans are bound by a river that binds the area. The nine clans are united by a unifying tool, the Siger Pepadun.

The nine clans are represented in the form of a siger pepadun as a symbol of unity. The music used departed from the wasp of the Lampung tradition which was composed according to the needs and interpretation of the stylist. The theme used is unity. Dance works are danced by ten dancers, nine men and one woman. Using kinesthetic stimuli and professional stimuli. The dramatic design is divided into three segments according to the needs of this work.The discovery of motion in this work is the discovery of new motion according to the work requirements of this work. Motion motives obtained are then processed according to the creativity and interpretation of the stylist. The work of Siwo

Megou's choreography arranged and danced in groups is a creation that is divided into three segments staged in the prosecenium stage on May 21, 2019.

Keywords: siwo megou, siger, cangget 


\section{PENDAHULUAN}

"Siwo Megou" adalah koreografi tari kelompok yang bersumber dari Siger Pepadun sebagai simbol persatuan dan merepresentasikan kesembilan buay yang ada di Lampung. Kata Siwo Megou terdiri dari kata Siwo dan Megou. Secara denotatif siwo berarti sembilan, dan megou berarti marga. Secara konotatif Siwo Megou melambangkan persatuan masyarakat Lampung yang tervisualkan pada siger (mahkota) pengantin perempuan Lampung. Makna di balik Siger Pepadun dilatarbelakangi oleh semboyan Sang Bumi Ruwai Jurai yang memiliki arti bumi dengan dua jurai (kelompok adat) yaitu Saibatin dan Pepadun. Lampung Pepadun memiliki lima kelompok buay ${ }^{1}$ yaitu Abung Siwo Megou, Pubian Telu Suku, Megou Pak Tulang Bawang, Sungkai Lima Suku, dan Way Kanan Lima marga. Likuk siwo yang berada di siger pepadun menyimbolkan kesembilan buay Abung Siwo Megou.

Di atas siger dipasang kembang hias berupa mahkota kecil bersusun tiga berbentuk menyerupai tanduk kerbau (Seraja Bulan) merupakan representasi dari marga Pubian Teluk Suku dan pada bagian ujung Ruji atau Likuk dipasang hiasan bunga kecil yang melambangkan lima keratuan/ kerajaan di Megou Pak Tulang Bawang, Sungkai Lima

\footnotetext{
1 Buay (berasal dari bahasa Lampung) berarti marga yang dipimpim oleh seorang kepala marga.
}

Suku, dan Way Kanan Lima Marga. Penata tertarik Abung Siwo Megou, yang memiliki arti sembilan buay Abung. Kesembilan buay ini mendiami daerah yang berbeda-beda.

Penata akan mengangkat makna di balik Siger Pepadun sebagai simbol persatuan dan merepresentasikan kesembilan buay yang diikat oleh satu sungai yang ada di Lampung biasa disebut Abung Siwo Megou. ${ }^{2}$ Kata "persatuan" menurut Kamus Besar Bahasa Indonesia (KBBI) ialah gabungan (sebuah ikatan atau kumpulan) beberapa bagian yang bersatu. Pernyataan ini sejalan dengan makna di balik siger pepadun yaitu simbol persatuan dari kesembilan buay yang dialiri satu sungai besar yaitu sungai Abung atau orang Lampung menyebutnya Way Abung.

Adapun ke-9 buay tersebut adalah Nunyai, Unyi, Nuban, Subing, Kunang, Anak Tuha, Selagai, Nyekhupa, dan Beliuk. ${ }^{3}$ Dari sembilan buay terdapat satu wanita, yaitu buay Nuban. Dalam salah satu acara cakak pepadun adat buay Nuban, terdapat penari laki-laki menari menggunakan siger dan tanggai sebagai bentuk penghormatan dan rasa cinta.

\footnotetext{
${ }^{2}$ Sabarudin, SA. 2012. Lampung Pepadun dan Sai Batin. Jakarta: Buletin Way Lima Manjau, 67.

${ }^{3}$ Sabaruddin SA. 2012. Lampung Pepadun dan Sai Batin. Jakarta: Buletin Way Lima Manjau. 29.
} 
Acara itu ialah igol, juga igol ialah tarian yang hanya dipentaskan oleh laki-laki. ${ }^{4}$

Kesembilan daerah tersebut dialiri oleh satu sungai besar yaitu sungai Abung masyarakat menyebutnya Way Abung. Menurut penata sungai tersebut bukan sebagai pemisah antara daerah satu dengan daerah yang lain, melainkan sebagai pemersatu dan sebagai pengikat daerah Abung. Sungai dianalogikan juga sebagai air yang akan mengukir jalannya sendiri dan tidak akan terputus dengan pedang setajam apapun, pada akhirnya ia (air) akan tetap bersatu kembali. Sungai juga ibarat tali yang mengikat daerah satu dengan lainnya. Menurut intepretasi penata terdapat makna persatuan, persaudaraan, toleransi, dan keagungan termaktub dalam kesembilan buay ini.

Penata juga menyisipkan karakter dari pedoman hidup masyarakat Lampung, yang masih digunakan oleh masyarakat Abung yaitu pi'il pesenggiri sebagai pandangan hidup atau falsafah masyarakat. Piil pesenggiri terdiri dari sakai sambayan (berjiwa sosial/tolong menolong), nemui nyimah (sopan santun/bagaimana bertingkah laku/bersikap), nengah nyapur (bergaul/bermasyarakat), bejuluk beadek (meningkatkan taraf hidup), bersifat terbuka dan fleksibel. Falsafah ini memiliki keterikatan dengan masyarakat

\footnotetext{
${ }^{4}$ Martiara, Rina. 2012. Nilai dan Norma Budya Lampung: dalam Sudut Pandang Strukturalisme. Yogyakarta: BP ISI Yogyakarta. X.
}

Lampung khususnya Abung. ${ }^{5}$ Piil pesenggiri merupakan potensi budaya sebagai sumber motivasi agar hidup dinamis dan memiliki nilai positif, hidup terhormat serta dihargai di masyarakat. ${ }^{6}$ Selain itu, Piil pesenggiri dapat diartikan sebagai rasa harga diri, juga sebagai aturan kebijakan dalam budi pekerti, tutur bahasa, tingkah laku seseorang akan dihargai oleh orang lain. ${ }^{7}$

Karya ini memiliki gagasan dasar penggambaran dari sembilan buay Abung dan menyisipkan karakter Piil Pesenggiri di dalamnya yang diikat oleh aliran sungai. Diawali dengan penggambaran suasana sebuah sungai, selanjutkan menggambarkan tentang sembilan buay tersebut dan membahas fenomena budaya yang ditangkap dari kebudayaan masyarakat setempat yaitu makna persatuan, persaudaraan, toleransi dan keagungan dan memvisualisasikan satu penari menggunakan siger dan jas sebagai penggambaran penghormatan terhadap buay Nuban, juga keterikatan antar kesembilan abung siwo megou. Sesuai dengan intepretasi penata bahwa persaudaraan merupakan sesuatu yang bersifat "agung" di dalamnya

\footnotetext{
${ }^{5}$ Friedrich W. Funke, 1958, Orang Abung. Terj Tim Isse. 2018. Orang Abung .Yogyakarta: Thafa Media, Xxiii

${ }^{6}$ BAPPEDA Kabupaten Lampung Tengah dan Lembaga Penelitian Universitas Lampung. 2003. Profil Budaya Masyarakat Lampung di Kabupaten Lampung Tengah . Metro: Dinas Pendidikan Pariwisata Seni dan Budaya Kabupaten Lampung Tengah, 19.

7 Rina Martiara. 2014. Nilai dan Norma Budaya Lampung. Yogyakarta: Badan Penerbit ISI Yogyakarta, xi.
} 
mengajarkan "toleransi" dalam lakunya, serta dapat menjadikan sebuah "kekuatan" sebab adanya "persatuan". Semua memiliki keterikatannya masing-masing.

Gerak yang digunakan sebagai pijakan dalam karya "Siwo Mego" ialah motif-motif gerak dari tari Cangget yaitu ngecum, sisir, kenuy ngelayang. Tari Cangget pada mulanya dihubungkan dengan kegiatan masyarakat yang telah terpola kemudian dikenal sebagai tarian milik adat pepadun. ${ }^{8}$ Tarian tersebut merupakan tarian yang berasal dari daerah Lampung pepadun.

Menurut penata terdapat keterkaitan antara siger dengan abung siwo megou, kesembilan daerah dengan sungai Way Abung, masyarakat abung dengan piil pesenggiri, masyarakat abung dengan tari cangget. Sehingga penata memilih tema keterikatan sebagai tema besar.

Pada karya "Siwo Mego" menggunakan musik tradisional daerah Lampung yaitu talo balak yang menggunakan Tabuh Tarei Lampung yang dipercantik dengan vokal guna memperkuat suasana yang ingin ditampilkan dan dioperasikan secara midi. Talo Balak merupakan seperangkat instrumen musik tabuhan yang sudah dikenal

${ }^{8}$ BAPPEDA Kabupaten Lampung Tengah dan Lembaga Penelitian Universitas Lampung. 2003. Profil Budaya Masyarakat Lampung di Kabupaten Lampung Tengah. Metro: Dinas Pendidikan Pariwisata Seni dan Budaya Kabupaten Lampung Tengah, 70 . di daerah Lampung. Organologi talo balak yaitu kelintang, gindang/gellitak (gendang), rujih, bende, tawak tawak, tala (gong). ${ }^{9}$ Karya ini akan menggunakan sembilan penari sembilan laki-laki dan satu perempuan dengan ketubuhan yang fleksibel. Menggunakan cara ungkap simbolis dengan tipe tari studi dramatik.

\section{PEMBAHASAN}

\section{A. Konsep Penciptaan Tari}

1. Rangsang Tari

Rangsang kinestetik berkaitan dengan ketertarikan pada beberapa motif gerak pada tari Cangget Lampung yang dianggap memiliki kapabilitas untuk dikembangkan dari berbagai sisi, salah satu contoh ialah gerak rebah pohon. Suatu gerak tetap memiliki gaya, suasana, pola atau bentuk dan aspek-aspek gerak yang dapat dikembangkan untuk membentuk sebuah karya tari. ${ }^{10}$ Di sisi lain ada rangsang gagasan atau ide yang dipetik dari sebuah siger pepadun yang di dalamnya terdapat sembilan marga yang berdiri samajajar. Gagasan ini selanjutnya mengarahkan pada hadirnya tema besar yaitu persatuan, yang menjadi acuan kreatif dalam

9 Taman Budaya Provinsi Lampung. 1996. Tabuhan Talo Balak. Bandar Lampung: Taman Budaya Provinsi Lampung, 3.

${ }^{10}$ Jaqueline Smith. 1985. Dance Composision; a partical guide for teachers, terj. Ben Surharto. Komposisi Tari: Sebuah Petunjuk Praktis Bagi Guru. Yogyakarta: Ikalasti. 22. 
pengekspresian setiap gerak atau rangkaian gerak yang bermakna.

\section{Tema Tari}

Tema merupakan pokok masalah yang hadir dari objek yang diangkat yaitu sembilan marga Abung sebagai makna di balik siger pepadun dan menyisipkan karakter Piil Pesenggiri di dalamnya. Berdasarkan hal tersebut, tema tari yang digunakan dalam karya ini adalah tentang keterikatan. Kesembilan buay Abung direpresentasikan ke dalam bentuk siger pepadun. Begitu pula dengan sungai yang mengalir kesembilan daerah tersebut bukan sebagai pemisah melainkan sebagai pengikat. Penata memiliki sub-tema yaitu persatuan, persaudaraan, kekuatan dan keagungan. Penata memposisikan tema pada karya sebagai ini salah satu bentuk agar pemusik, penari dan segala yang terlibat menjadi sebuah satu kesatuan yang terikat, yang sesuai dengan tema yaitu keterikatan.

\section{Judul Tari}

Sembilan marga besar Abung merupakan makna yang terkandung di balik bentuk likuk/ruji dari siger pepadun. Di mana masing-masing daerah tersebut dialiri oleh satu sungai besar. Ke 9 daerah tersebut memiliki marga masing-masing. Penata mengambil judul "Siwo Mego" dari bahasa Lampung yang artinya Sembilan marga.

\section{Bentuk Tari}

Karya ini menyuguhkan tipe studi yang divisualisasikan melalui pengembangan gerak yang berangkat dari unsur gerak dasar tari Cangget Lampung. Koreografi ini akan menggambarkan tentang suasana-suasana tertentu. Suasana pada saat di sungai, daerah kesembilan buay Abung, dan intrepretasi penata tentang persatuan kesembilan marga Abung.

\section{Konsep Garap Tari 1. Gerak Dasar}

Gerak dasar yang akan digunakan sebagai pijakan pada koreografi ini adalah gerak dari Tari Cangget dengan mengambil esensi gerak tangan. Dengan menggunakan gerak cangget, sesungguhnya tetap saja muncul gerak-gerak yang memvisualisasikan alur cerita, dan tidak dipungkiri bahwa karya ini membutuhkan gerak wantah yang telah distilisasi untuk mendukung penyampaian pesan terhadap penonton sehingga gerak yang muncul terkesan tidak melulu menggunakan teknik dari Tari Cangget. Gerak dari tari Cangget ialah ngecum, sisir, dan kenuy ngelayang.

Berdasarkan hal di atas, masingmasing penari melakukan gerak yang menggambarkan alur cerita dan alur suasana yang dimunculkan dengan gerak dasar tari 


\section{JOGED}

ISSN: $1858-3989$

Cangget dengan distilisasi dan divariasikan berdasarkan ruang, waktu dan tenaga. Fokus pencarian gerak pada karya ini adalah penggambaran alur suasana sungai yang mengaliri kesembilan daerah tersebut, penggambaran ciri-ciri dari setiap daerah tersebut, kemudian terakhir penggambaran persatuan masyarakat yang ada di daerah Abung. Pada segmen pertama penata menggambarkan sebuah alur suasana sungai yang menggaliri kesembilan daerah tersebut dengan menggunakan gerak-gerak yang lebih mengalun dan merupakan distilisasi dari tari Cangget.

\section{Jumlah Penari}

Kesembilan daerah Abung memiliki sembilan marga yang berbeda-beda pula. Kemudian dari kesembilan buay itu direpresentasikan ke dalam bentuk sebuah pucuk/ruji siger yang berjumlah sembilan. Kesembilan buay tersebut dialiri oleh satu sungai yang penata ambil sebagai pemersatu. Berdasarkan kesembilan buay Abung mengarah ditetapkannya jumlah penari yaitu Sembilan orang penari, delapan laki-laki dan 1 perempuan. Kesembilan penari delapan lakilaki dan satu perempuan menyimbolkan sembilan buay dan laki-laki yang menggunakan siger merupakan simbol persatuan.
SIWO MEGOU: KOREOGRAFI SIGER PEPADUN LAMPUNG

Pemilihan penari dilakukan dengan kualifikasi yaitu penari haruslah paling tidak mengetahui cerita yang akan diangkat, kemudian bisa melakukan gerak-gerakan kaki, dan juga tidak terlalu kaku. Karakter yang akan ditonjolkan adalah penari yang bisa tegas dan tidak kaku ketika bergerak lembut. Seluruh penari juga harus memiliki stamina yang prima. Tak hanya itu, kemampuan penari untuk mengikuti kemampuan ketubuhan penata juga menjadi pertimbangan penata. Hal tersebut juga dapat menguatkan penyampaian pesan dalam karya tari ini, karena hal dapat mendukung penonjolan dan alur suasana yang akan diangkat.

3. Musik tari

Peran musik iringan salah satunya adalah untuk mendukung penebalan ritme yang membantu penari pada tekanan nada dan ketukan serta mendukung suasana kepada penonton. Musik dalam karya ini memakai instrumen musik tradisi daerah Lampung seperti Gambus lunik, Gamolan, Kompang, Cetik, Gong dan Ghuhijk. Instrumen-intrumen ini diekplorasi berdasarkan pola Tabuh Tarei Lampung yang dikembangkan. Hal ini bertujuan untuk menguatkan rasa dan spirit Lampung dalam karya ini. Serta menggunakan vokal yang berisikan tentang ciri-ciri khas dari setiap daerah Abung untuk memperkuat suasana. Musik dimainan secara midi. 


\section{Rias dan Busana}

Karya tari ini merupakan karya tari yang memberikan gambaran alur suasana dan juga kesembilan daerah Abung yang berada di Lampung. Busana dalam karya ini menggunakan Kain Abung (bahan dasar untuk membuat tapis yang didominasi warna hitam dan merah dalam bentuk garis-garis). Kain Abung tersebut akan didesain dan diberi kain tapis khas Lampung yang dibuat secara sama tanpa pembeda. Busana yang akan dikenakan dan didesain melekat pada tubuh guna mempermudah penari dalam melakukan suatu gerakan yang sudah dijelaskan sebelumnya. Warna hitam dan merah merupakan warna khas dari daerah Abung kemudian kain tapis juga merupakan kain khas dari Lampung. Rias wajah penari disesuaikan dengan konsep cerita yang disuguhkan, sehingga menggunakan make up korektif yang tidak terlalu tebal juga tidak terlalu tipis.

\section{e. Pemanggungan}

Tempat pementasan karya ini adalah proscenium stage Jurusan Tari Institut Seni Indonesia Yogyakarta. Konsep blackbox dari proscenium stage ini membuat mata manusia maupun mata kamera dapat memunculkan imajinasi 'ruang' yang tidak terbatas. Bentuk perspektif dari proscenium stage ini mempermudah penata dalam penguasaan ruang, seperti pola lantai dan arah hadap dengan satu sudut pandang karena memiliki satu arah hadap dari penonton. Pemilihan panggung ini mempertimbangkan bahwa karya ini merupakan Karya Tugas Akhir sebagai syarat kelulusan di Program Studi S1 Seni Tari, sehingga pelaksanaannya pun dilaksanakan di Jurusan Seni Tari Institut Seni Indonesia Yogyakarta. Panggung yang sudah disediakan untuk pementasan karya ini akan dimanfaatkan sesuai dengan perspektif proscenium stage yang seharusnya tanpa menambah setting atau batasan-batasan tertentu.

\section{Wujud Koreografi}

Segmen pertama membahas tentang sifatsifat air seperti yang sudah dibahas di atas bahwa sifat air yaitu saling mengisi, fleksibel, dan mengikuti arah/arus. Segmen pertama dimulai dari Sembilan penariberjalan kearah depan rampak simultan. Pada saat yang persamaan juga frontcurtain membuka secara perlahan. Pola lantai yang lebih mengisi ruang, sesuai dengan sifat air yang telah dijelaskan oleh bagan kedua. Segmen kedua membahas tentang persaudaraan, toleransi. Nuansa musik yang digunakan ialah lebih dominan alat musik perkusi agar terlihat lebih bersemangat dan lebih mendapatkan spirit dari persaudaraan itu sendiri. Gerak yang digunakan pun juga lebih kompleks dari gerak pada segmen pertama. segmen ketiga 


\section{JOGED}

membahas tentang keagungan dan kekuatan yang merupakan pokok menjadi sebuah persatuan. Musik pada bagian ini cenderung menggunakan musik perkusi, dandan pada bagian akhir terdapat lirik yang berisi tentang kesembilan marga siwo megou. Bagian akhir karya/segmen ketiga terdapat satu penari lakilaki menggunakan jas, dan menggunakan Siger sebagai bentuk penghormatan terhadap buay Nuban dan juga sige simbol yang merepresentasikan persatuan.

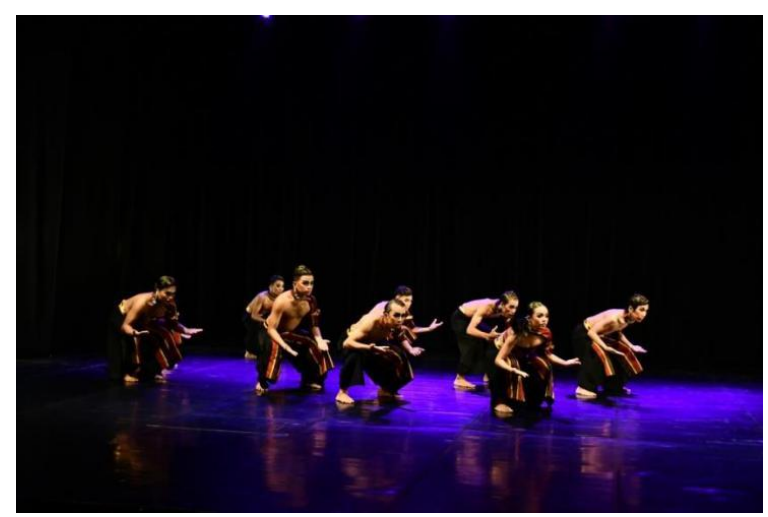

Gambar 1: Salah satu motif gerak Jatuh Air pada segmen pertama

(Dokumentasi: Anto, Yogyakarta 2019)
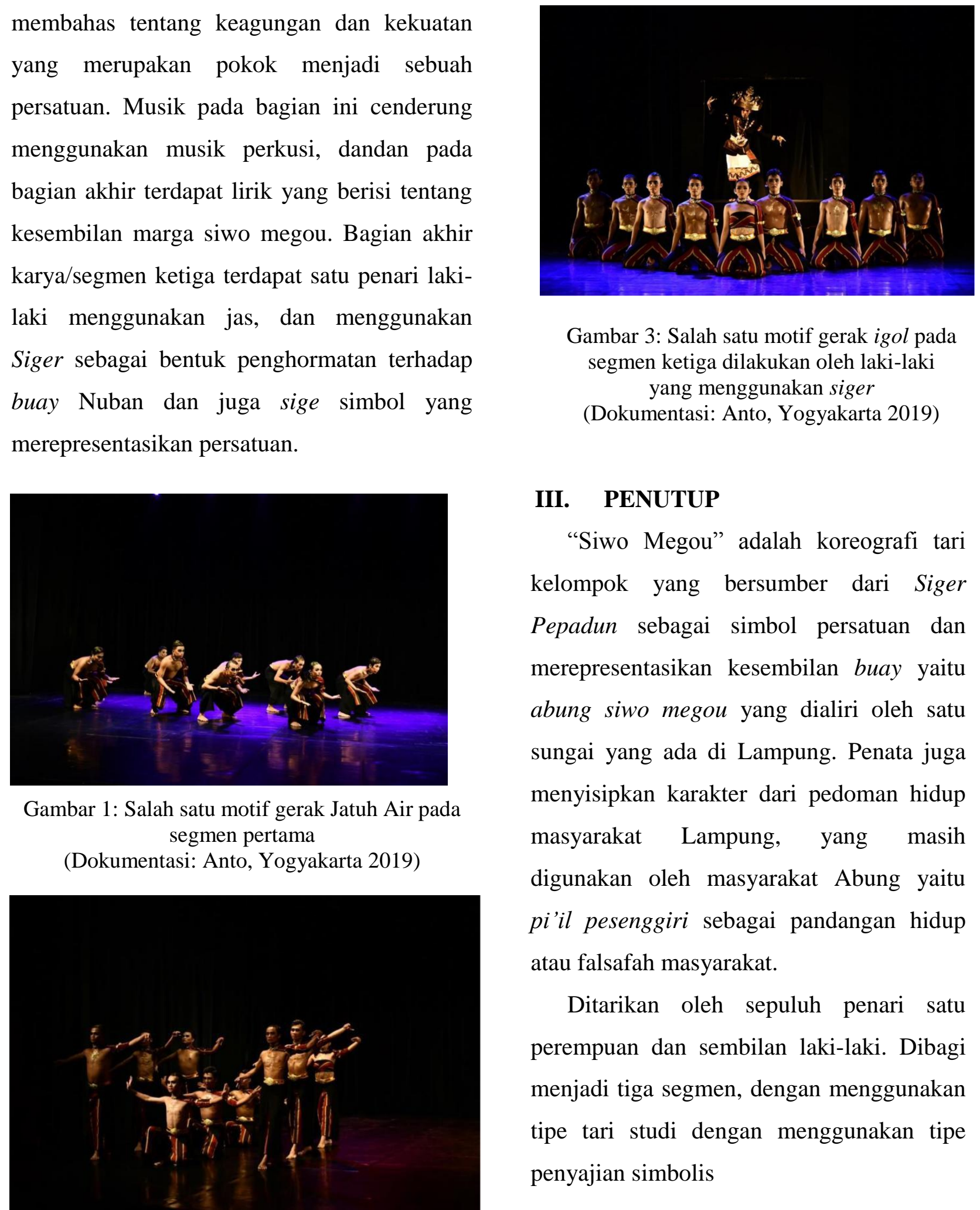

Gambar 3: Salah satu motif gerak igol pada segmen ketiga dilakukan oleh laki-laki yang menggunakan siger

(Dokumentasi: Anto, Yogyakarta 2019)

\section{PENUTUP}

"Siwo Megou" adalah koreografi tari kelompok yang bersumber dari Siger Pepadun sebagai simbol persatuan dan merepresentasikan kesembilan buay yaitu abung siwo megou yang dialiri oleh satu sungai yang ada di Lampung. Penata juga menyisipkan karakter dari pedoman hidup masyarakat Lampung, yang masih digunakan oleh masyarakat Abung yaitu pi'il pesenggiri sebagai pandangan hidup atau falsafah masyarakat.

Ditarikan oleh sepuluh penari satu perempuan dan sembilan laki-laki. Dibagi menjadi tiga segmen, dengan menggunakan tipe tari studi dengan menggunakan tipe penyajian simbolis

Gambar 2: Salah satu motif gerak Ngecum Berjalan pada segmen kedua

(Dokumentasi: Anto, Yogyakarta 2019) 


\section{DAFTAR SUMBER ACUAN}

\section{A. Sember Tercetak}

BAPPEDA Kabupaten Lampung Tengah dengan Lembaga Penelitian Universitas Lampung. 2013. Profile Budaya Masyarakat Lampung di Kabupaten Lampung Tengah. Lampung Tengah: Dinas Pendidikan Pariwisata Seni dan Budaya.

Funke, W Friedrich. 1958. Orang Abung: Volkstum Sud-Sumatras im Wandel, terj. Tim Isse. 2018. Orang Abung: Cerita Raykat Sumatera Selatan dari Waktu ke Waktu. Yogyakarta: Thafamedia.

Hadi, Y. Sumandiyo. 2003. Aspek-Aspek Dasar Koreografi Kelompok. Yogyakarta: Elkaphi.

Hadi, Y. Sumandiyo. 2014.

Kajian Tari Teks dan Konteks. Yogyakarta: Cipta Media.

Hadi, Y. Sumandiyo. 2014.

Koreografi Bentuk-Teknik-Isi. Yogyakarta: Cipta Media.

Hadi, Y. Sumandiyo. 2017.

Koreografi Ruang Prosenium. Yogyakarta: Cipta Media.

Hawkins, Alma. 1990. Moving From Within: A New Method for Dance Making, terj. I Wayan Dibia. 2003. Bergerak Menurut Kata Hati: Metode Baru dalam Menciptakan Tari. Jakarta: MSPI.

Hawkins, Alma. 1990. Creating Through Dance, terj. Y. Soemandiyo Hadi. Yogyakarta: ISI Yogyakarta.
Humprey, Doris. 1983. Seni Menata Tari, terj. Sal Murgiyanto. Dewan Kesenian Jakarta.

Martiara, Rina. 2012. Nilai dan Norma Budaya Lampung: dalam Sudut Pandang Strukturalisme. Yogyakarta: Program Pascasarjana ISI Yogyakarta.

Martiara, Rina. 2014. Cangget: Identitas Kultural Lampung Sebagai Bagian Dari Keragaman Budaya Indonesia. Yogyakarta: ISI Yogyakarta.

Martono, Hendro. 2012. Ruang Pertunjukan dan Berkesenian. Yogyakarta: Cipta Media.

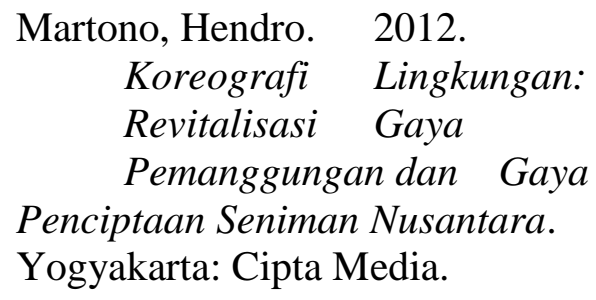

Martono, Hendro. 2015. Mengenal Tata Cahaya Seni Pertunjukan. Yogyakarta; Cipta Media.

Meri, La. 1976. Dance Composition: The Basic Elements, terj. Soedarsono. Yogyakarta: Akademi Seni Tari Indonesia.

Murgiyanto, Sal. 1983. Koreografi Pengetahuan Dasar Komposisi Tari. Yogyakarta: Departemen Pendidikan dan Kebudayaan.

Raditya, Ardhie. 2014. Sosiologi Tubuh. Yogyakarta. Kaukaba.

RMA, Haryawan. 1993. Dramaturgi. Bandung: PT Remaja Rosda Karya. 
Sedyawati, Edi. 2010. Budaya Indonesia: Kajian Antropologi, Seni, dan Sejarah. Jakarta: PT. Raja Grafindo.

Soedarsono, R.M, dkk. 1986.Pengetahuan Elementer Tari dan Beberapa Masalah Tari. Direktorat Kesenian Proyek Pengembangan Kesenian Jakarta: Departemen Pendidikan dan Budaya.

Smith, Jaqueline. 1985. Dance Composision; a partical guide for teachers, terj. Ben Surharto.

Yogyakarta: Ikalasti.

Sumardjo, Jakob. 2000. Filsafat Seni.

Bandung: ITB.

Sumardjo, Jakob. 2006. Estetika

Paradoks. Bandung: Sunan Ambu Press.

Taman Budaya Provinsi Lampung. 1996

Tabuhan Talo Balak. Lampung:

Taman Budaya Provinsi Lampung.

Wayan, I Mustika. 2012. Teknik

Dasar Gerak Tari Lampung. Bandar

Lampung: AURA.

Widaryanto, F.X. 2009. Koreografi.

Bandung: Jurusan Tari STSI

Bandung.

\section{B. Narasumber}

1. Nama : Tadjuddin Nur,

$\mathrm{SH}$

Nama Gelar : Suttan Sang

Bimojagat Rasobayo

Tempat,

Tanggal Lahir : Sukadana, 6

November 1956

Alamat : Jl. Kiwi no. 45

Kel. Sidodadi Bandar Lampung

35147

Pekerjaan : PNS dan

Budayawan
KOREOGRAFI SIGER PEPADUN LAMPUNG

2. Nama : Sandika Ali

S.Pd., M.Pd.

Tempat,

Tanggal Lahir : 23 November

1994

Alamat : Jl. Rusa LK.II

Perumahan Griya Sukamenanti

Pekerjaan : Seniman dan

Budayawan

\section{Sumber Webtografi}

http://kutobumei.blogspot.com/2011

/10/panggeh-kebuayan-abung-

siwou-migou.html diakses tanggal

20 September 2018

D. Sumber Diskografi

https://www.youtube.com/watch?v

$=$ raEDLI-jHko judul Tari

Cangget Lampung diunggah pada

tanggal 22 Januari 2017

https://www.youtube.com/watch?v

=ViTffKO5UOo judul Tari

Cangget Pepadun diunggah pada

tanggal 23 September 2017 